\begin{tabular}{|c|c|c|}
\hline & International Journal of Current Research in \\
Biosciences and Plant Biology \\
EXCELLENT \\
PUBLISHERS
\end{tabular}

\title{
Green Synthesis of Silver Nanoparticles Using Seed Extract of Foeniculum vulgare and their Antibacterial Activity
}

\author{
R. Nigar Sulthana* and A. Rajanikanth
}

Department of Biotechnology, SPW Degree \& PG College, Tirupati - 517 502, Andhra Pradesh, India

${ }^{*}$ Corresponding author.

\begin{tabular}{|c|c|}
\hline Article Info & \multirow{4}{*}{$\begin{array}{l}\text { In this article, we report an ecofriendly technique for the preparation of silver } \\
\text { nanoparticles (AgNPs) using seed extract of Foeniculum vulgare, and the evaluation of } \\
\text { their antibacterial activity. UV-visible spectroscopy, SEM and FTIR analysis were used } \\
\text { to characterize the morphology and crystalline phase of AgNPs. Reduction of silver } \\
\text { ions using seed extract of Foeniculum vulgare resulted in the synthesis of nanoparticles. } \\
\text { The seed extract showed an absorption peak at } 475 \mathrm{~nm} \text { in UV-VIS spectrum } \\
\text { corresponding to the plasmon resonance of silver nanoparticles. FTIR spectrum } \\
\text { showed the involvement of amides and amines in capping and reduction of silver } \\
\text { nanoparticles. Antibacterial activity was screened using synthesized silver } \\
\text { nanoparticles against Staphylococcus aureus, Escherichia coli and Pseudomonas aeruginosa. } \\
\text { The AgNPs showed potent antibacterial activity against different types of bacteria. The } \\
\text { results confirmed that Foeniculum vulgare is a potential bio-resource/biomaterial for } \\
\text { synthesizing AgNPs with applications in antibacterial agents. }\end{array}$} \\
\hline $\begin{array}{l}\text { Date of Acceptance: } \\
\text { 11 June } 2018\end{array}$ & \\
\hline Keywords & \\
\hline $\begin{array}{l}\text { Antibacterial assay } \\
\text { Biosynthesis } \\
\text { Foeniculum vulgare } \\
\text { Silver nanoparticles }\end{array}$ & \\
\hline
\end{tabular}

\section{Introduction}

In the last two decades, nanotechnology and nanoparticle research has become one of the most important areas in modern materials science research. It has attracted considerable interest in the fields of electronics, biology, and medicine, due to the distinctive properties of nanoparticles, such as optical, antimicrobial, cancer therapeutic, and catalytic properties (Abdel-Mohsen et al., 2012; Jacob et al., 2012).
Currently, metal nanoparticles with their unparalleled characteristics are extensively studied owing to their potential applicability in diverse areas such as packaging, coatings, biological tagging, and pharmaceutical applications (Chen et al., 2007; Gopinath et al., 2012). Nowadays increasing awareness has been started towards green chemistry and other biological processes for the synthesis of nanomaterials (Zhang et al., 2011; Hsiao et al., 2006; Egorova and Revina, 2000). Even though numerous types of nanomaterials like 
silver, copper, zinc, titanium, magnesium, gold, alginate have come up but silver nanoparticle have proven to be most effective as it has good antimicrobial efficacy against bacteria, fungi, virus and other eukaryotic microorganism (Jose et al., 2005). Foeniculum vulgare (Fennel) is a plant species of the genus Foeniculum, which belong to the family Apiaceae. It is a hardy, perennial, umbelliferous herb, with yellow flowers and feathery leaves. It is a highly aromatic and flavorful herb with culinary and medicinal uses. Florescence as well as stem base is used as vegetables. Extracts of fennel seed have been shown in animal studies to have a potential use in the treatment of glaucoma, cancer and diabetes. Fennel may be an effective diuretic and a potential drug for treatment of hypertension (Rodrigues et al., 2003).

To the best of our knowledge, the use of fennel seed extract for the green synthesis of novel metal nanoparticles such as silver nanoparticles has not been reported. It is important to study the formation of nanoparticles in fennel seed extract for the understanding of the mechanism of biological synthesis and for exploring new green ways to prefabricate nanomaterials. So, in the present study we report green synthesis, characterization of silver nanoparticles and evaluation of antibacterial activities of synthesized silver nanoparticles.

\section{Materials and methods}

\section{The plant material}

Seeds of Foeniculum vulgare were collected from the plant grown in garden of SPW Degree and PG College, Tirupati. Seeds were washed, sundried, finely powdered and used for the synthesis of silver nanoparticles.

\section{Preparation of plant extract}

Seed powder weighing $5 \mathrm{~g}$ of was taken and mixed with $50 \mathrm{ml}$ of sterile distilled water. The mixture was ground using mortar and pestle. The ground mixture was filtered through Whatman No.1 filter paper (pore size $25 \mu \mathrm{m}$ ). The filtrate was further filtered through $0.6 \mu \mathrm{m}$ sized filters and used for present investigation.

\section{Preparation of silver nitrate solution}

$1 \mathrm{mM}$ silver nitrate solution was freshly prepared by using sterile distilled water.

\section{Synthesis of silver nanoparticles}

For biosynthesis of nanoparticles, $10 \mathrm{ml}$ seed extract was mixed with $90 \mathrm{ml}$ of silver nitrate $(1 \mathrm{mM})$ in a sterile conical flask and kept in dark condition at room temperature.

\section{Characterization of silver nanoparticles}

\section{UV-VIS spectra analysis}

The reduction of pure silver ions ( $\mathrm{Ag}+$ ions) was monitored by measuring the UV-VIS spectrum of the reaction medium after 3 hours incubation after diluting a small aliquot of the sample into distilled water $(1: 9)$.

\section{FTIR analysis}

The sediment layers were characterized by FTIR (Model: Spectrum RXI). The FTIR spectrum was obtained in the mid IR region of $400-4000 \mathrm{~cm}^{-1}$. The spectrum was recorded using ATR (Attenuated Reflectance Technique). The dried experimental sample was directly placed on the potassium bromide crystals and the spectrum was recorded in transmittance mode.

\section{SEM analyses}

SEM analysis was done using software controlled Scanned Electron Microscope. The energy of electron beam current was continuously adjusted from $1 \mathrm{pA}$ to $1 \mu \mathrm{A}$ to suit the type of examination in progress. Thin film of the sample was prepared by using drop coating method on a carbon coated copper grid by just dropping very small amount of the sample on the grid. The film on the SEM grid was allowed to dry by putting it under a mercury 
lamp for 5 min. Each sample was analyzed by the SEM.

\section{Antimicrobial activity of silver nanoparticles}

Growth inhibition studies against both Gram positive (Staphylococcus aureus) and Gram negative (Escherichia coli and Pseudomonas aeruginosa) of silver nanoparticles were carried out in LB broth media. The experiments were conducted according to the following procedure, with some modifications. In order to maintain the initial bacterial concentration within the same range, in each sterile $100 \mathrm{~mL}$ Erlenmeyer flask, 50 $\mathrm{mL}$ of $\mathrm{LB}$ broth media and silver nanoparticles ranging from 5 to $40 \mu \mathrm{g} / \mathrm{mL}$ were mixed with $1 \mathrm{~mL}$ of freshly prepared bacterial suspension. Then, the flasks were incubated at $150 \mathrm{rpm}$ at $37^{\circ} \mathrm{C}$ in a rotary shaker. A flask containing only the broth media and bacteria was used as the control. The growth of the bacteria was monitored at $600 \mathrm{~nm}$ every hour for 9 hours using a UV-Vis spectrophotometer.

\section{Results and discussion}

\section{UV-VIS spectroscopy}

Addition of plant extract to the aqueous $1 \mathrm{mM}$ silver nitrate solution turned the solution to brown colour indicating the formation of Ag nanoparticles (Jae et al., 2009; Kamat et al., 1998). The reaction mixtures developed an array of colour after 3 hours of incubation under dark condition (to minimize photoactivation of silver nitrate), at $37^{\circ} \mathrm{C}$ temperature (Fig. 1).

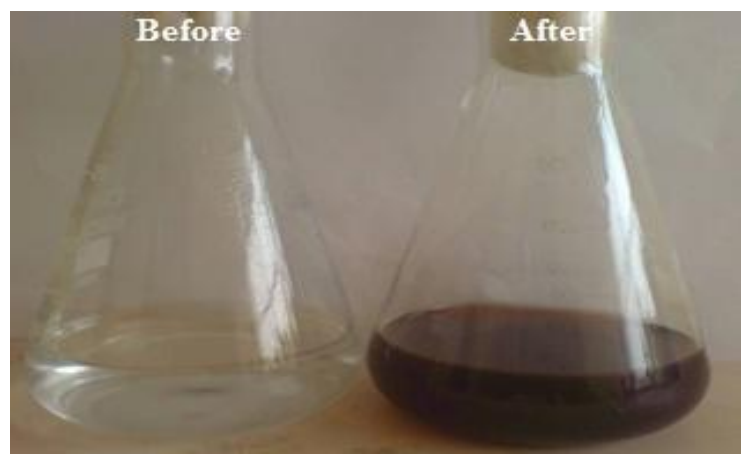

Fig. 1: Visual observation indicating the synthesis of silver nanoparticles using Foeniculum vulgare seed extract.
In UV-VIS spectroscopy the peak was observed in the range of $425 \mathrm{~nm}$ (Fig. 2). The visual observation and UV-VIS spectra were thus indicative of nanoparticles synthesis. Silver nanoparticles are known to display vivid colour due to the phenomenon of Surface Plasmon Resonance (Agnihotri et al., 2009).

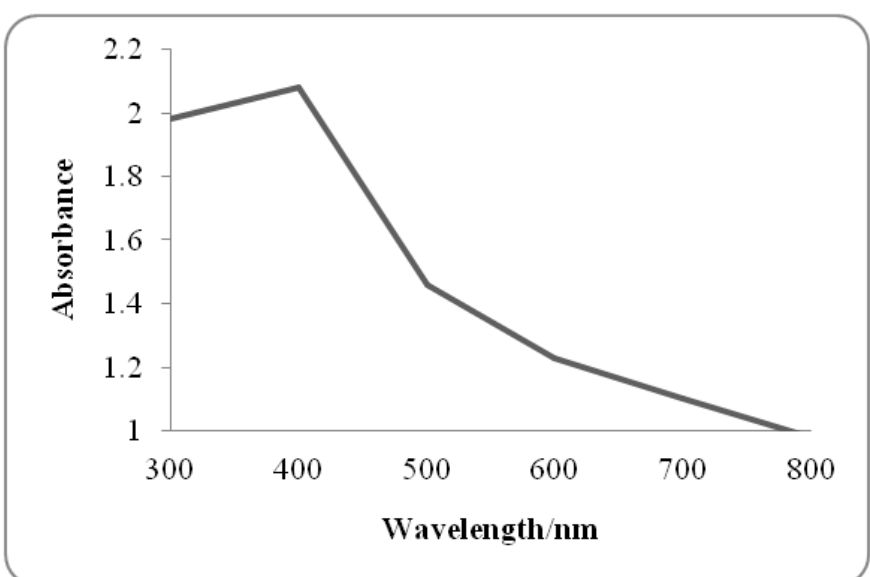

Fig. 2: The UV-Vis spectra of reduction of $\mathrm{Ag}$ ions to Ag nanoparticles seed extract with silver nitrate at different time points of incubation.

\section{Fourier Transforms Infra Red (FTIR) analysis}

FTIR has emerged as a valuable tool for understanding the involvement of surface functional groups in metal interactions. This technique was applied to determine the groups that were present in Foeniculum vulgare seed extract and to predict their role in the synthesis of silver nanoparticles (Philip, 2009; Tripathy et al., 2010). FTIR analysis revealed the presence of three bonds at $548.38 \mathrm{~cm}^{-1}, 1636.17 \mathrm{~cm}^{-1}$ and $3347.85 \mathrm{~cm}^{-1}$ (Fig. 3). The peak at $548.38 \mathrm{~cm}^{-1}$ is in the fingerprint region. The band obtained at $1636.1 \mathrm{~cm}^{-}$ 1 is due to the carbonyl stretch vibrations in the amide linkages of the proteins, respectively (Basavaraja et al., 2008). The other band found at $3347.85 \mathrm{~cm}^{-1}$ is due to the stretching vibrations of primary amines (Vigneshwaran et al., 2007). The FTIR spectroscopic study has confirmed that the carbonyl group from amino acid residues and peptides of proteins has the stronger ability to bind to metal. So that the proteins could most possibly from a coat covering the metal nanoparticles 
(i.e., Capping of silver nanoparticles) to prevent the agglomeration of particles and stabilizing them in the medium. This evidence suggests that the biological molecules could possibly perform the function for the formation and stabilization of the silver nanoparticles in aqueous medium.

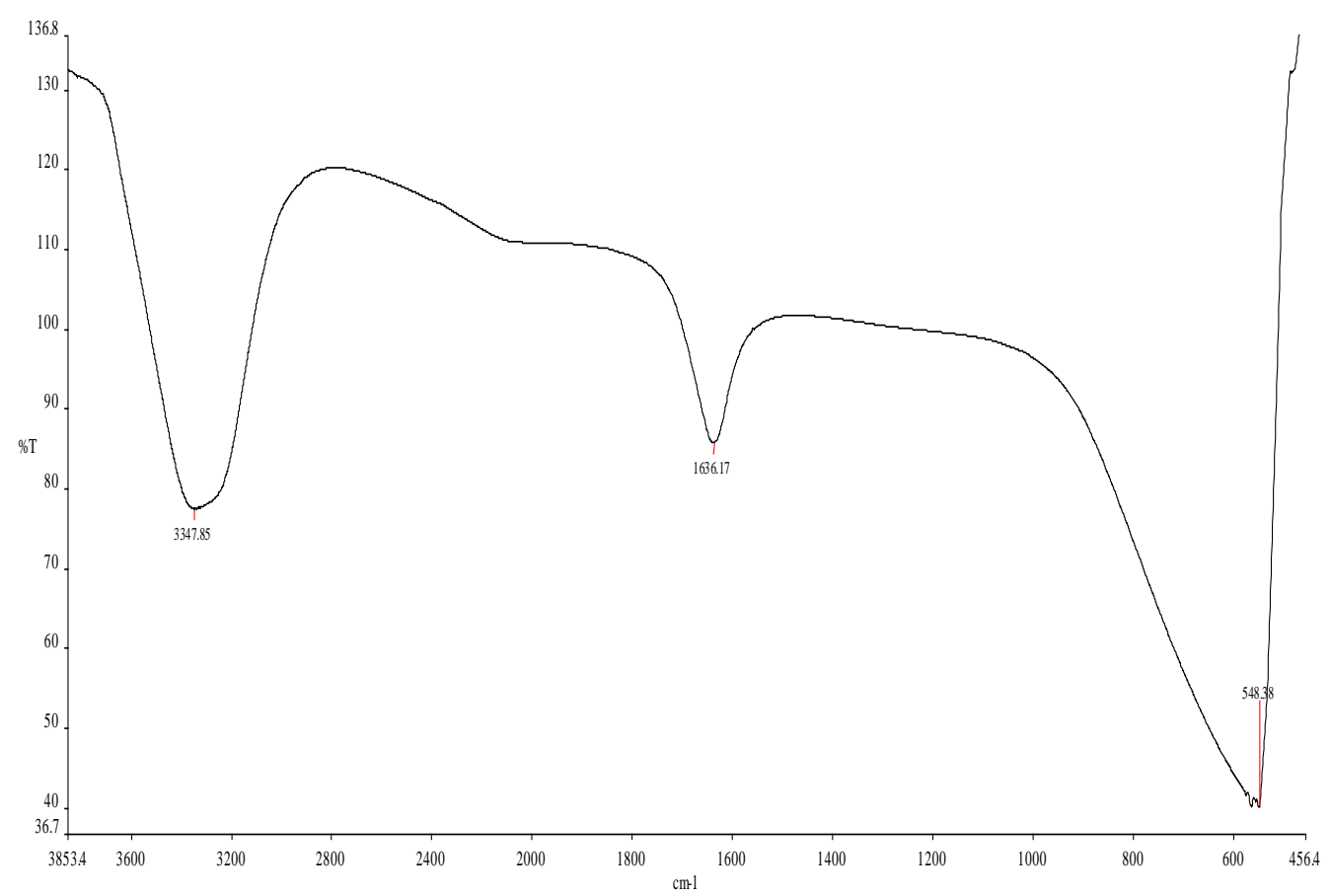

Fig. 3: FTIR spectra of silver nanoparticles synthesized using seed extract of Foeniculum vulgare.

\section{Scanning Electron Microscope (SEM) analysis}

The SEM analysis was used to determine the structure of the reaction products that were formed. SEM image has showed individual silver particles as well as a number of aggregates. The SEM image showed relatively spherical shape nanoparticle formed with diameter range 11-25 nm (Fig. 4). Similar phenomenon was reported by Shiv Shankar et al. (2004).

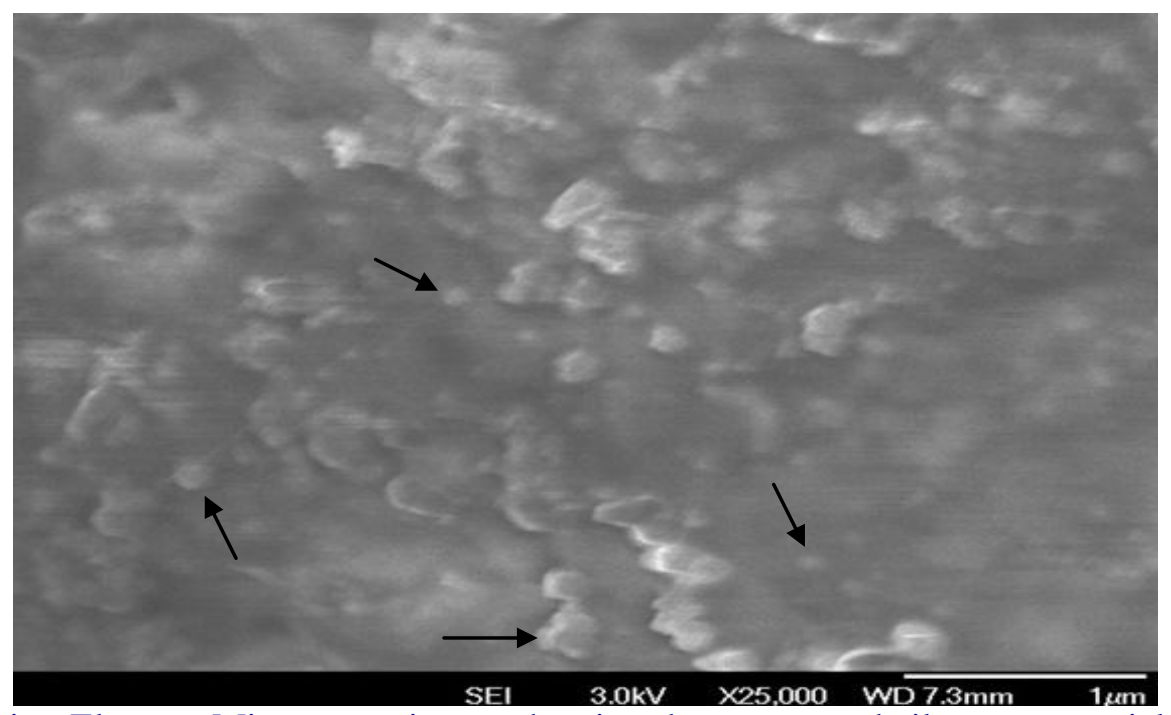

Fig. 4: Scanning Electron Microscopy image showing the aggregated silver nanoparticles of roughly spherical shape and the black arrows pointing some of the nanoparticles of different sizes. 


\section{Antibacterial activity of synthesized silver nanoparticles}

The antibacterial properties of synthesized AgNPs were assessed against both the Gram-positive bacterium $S$. aureus and the Gram-negative bacteria $E$. coli and $P$. aeruginosa. Optical densities of the three pathogens were measured for 9 hours at regular intervals with different concentrations of AgNPs from 0 to $40 \mu \mathrm{g} / \mathrm{ml}$, which were plotted as a function of time as shown in Fig. 5. The AgNPs exhibited dose dependent antibacterial activity against all three pathogens, with very fast killing kinetics in comparison with the control. The same minimum inhibition concentration (MIC) was observed for S. aureus and E. coli to be $20 \mu \mathrm{g} / \mathrm{mL}$
(Fig. 5a and b), whereas it was observed to be 40 $\mu \mathrm{g} / \mathrm{mL}$ for $P$. aeruginosa (Fig. 5c). In all three cases, there was obviously no bacterial growth in 7 hours with $40 \mu \mathrm{g} / \mathrm{mL}$ of AgNPs as the effective bactericides. While the antibacterial activity decreased significantly in the case of $P$. aeruginosa after 7 hours of treatment, the percent inhibition for $S$. aureus and E. coli remained the same as at the beginning. Taking into account the previously synthesized AgNPs with potent bactericidal activity obtained by using the Artocarpus heterophyllus seed (Jagtap and Bapat, 2013), Cinnamon zeylanicum bark (Mosmann, 1983) and so on, it is fair to say that synthesized AgNPs are a good antibacterial bio-resource with potential applications in biomedical and related areas.
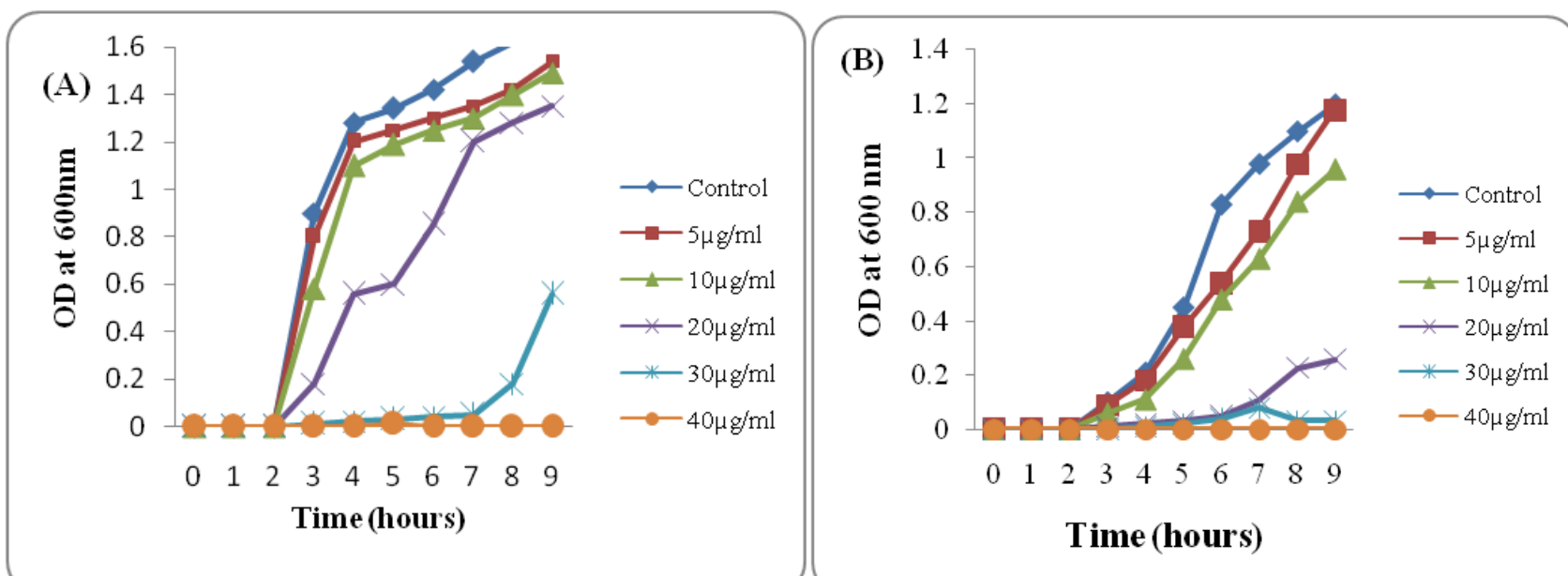

Time (hours)

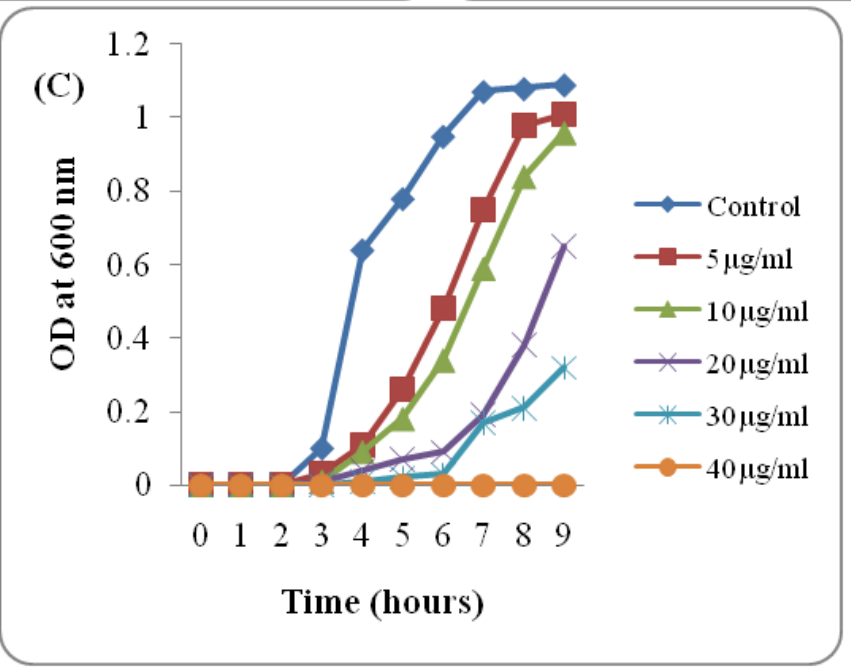

Fig. 5: Batch growth profiles of (a) S. aureus, (b) E. coli and (c) P. aeruginosa at various concentrations of AgNPs for a time period of 9 hours. 


\section{Conclusion}

In summary, this study demonstrated an ecofriendly, rapid, green approach to the synthesis of AgNPs by using Foeniculum vulgare, which supplies a simple, cost-effective and ecological method for the synthesis of AgNPs. Water-soluble secondary metabolites, most likely flavonoids or proteins, in Foeniculum vulgare were mainly responsible for the biosynthesis of AgNPs. The AgNPs so-prepared exhibited effective antibacterial activity, suggesting AgNPs might be useful as a silver dressing for wounds or as an alternative material. Therefore, further investigations are needed to fully characterize the cytotoxicity and the mechanism of action associated with the antioxidant and antibacterial activity of their particles.

\section{Conflict of interest statement}

Authors declare that they have no conflict of interest.

\section{References}

Abdel-Mohsen, A. M., Hrdina, R., Burgert, L., Krylová, G., Abdel-Rahman, R. M., Krejčová, A., Beneš, L., 2012. Green synthesis of hyaluronan fibers with silver nanoparticles. Carbohyd. Polymer. 89(2), 411-422.

Agnihotri, M., Joshi, S.S., Kumar, A.R., Zinjarde, J., Kulkarni, S., 2009. Banana peel extract mediated synthesis of gold nanoparticles. Coll. Surf. B: Biointer. Mat. Lett. 63, 1231.

Basavaraja, S., Balaji, S.D., Lagashetty, A., Rajasab, A.H., Venkataraman, A., 2008. Extracellular biosynthesis of silver nanoparticles using the fungus Fusarium semitectum. Mater. Res. Bull. 43, 1164-1170.

Chen, J., Wang, D., Xi, J., Au, L., Siekkinen, A., Warsen, A., Li, X., 2007. Immuno gold nanocages with tailored optical properties for targeted photothermal destruction of cancer cells. Nano Lett. 7(5), 1318-1322.

Egorova, E.M., Revina, A.A., 2000. Synthesis of metallic nanoparticles in reverse micelles in the presence of quercetin. Coll. Surf. A. 168, 87-96. Gopinath, V., MubarakAli, D., Priyadarshini, S., Priyadharsshini, N. M., Thajuddin, N., Velusamy, P., 2012. Biosynthesis of silver nanoparticles from Tribulus terrestris and its antimicrobial activity: A novel biological approach. Coll. Surf. B: Biointer. 96, 69-74.

Hsiao, M.T., Chen, S.F., Shieh, D.B., Yeh, C.S., 2006. One-pot synthesis of hollow $\mathrm{Au}_{3} \mathrm{Cu}_{1}$ spherical-like and biomineral botallackite $\mathrm{Cu}_{2}$ $(\mathrm{OH})_{3} \mathrm{Cl}$ flower-like architecture exhibiting antimicrobial activity. J. Phy. Chem. B. 110, 250-210.

Jacob, S. J. P., Finub, J. S., Narayanan, A., 2012. Synthesis of silver nanoparticles using Piper longum leaf extracts and its cytotoxic activity against Hep-2 cell line. Coll. Surf. B: Biointer. 91, 212-214.

Jae, Y.S., Beom, S.K., 2009. Rapid biological synthesis of silver nanoparticles using plant leaf extracts. Bioprocess Biosyst. Engg. 32, 79-84.

Jagtap, U. B., Bapat, V. A., 2013. Green synthesis of silver nanoparticles using Artocarpus heterophyllus Lam. seed extract and its antibacterial activity. Industr. Crops Prod. 46, 132-137.

Jose, R.M., Ghodake, V.P., Jose, L.E., Alejandra, C., 2005. Biosynthesis of silver nanoparticles using Trichosporon beigelii NCIM 3326 and evaluation of their antibacterial activity. Nanotech. 16, 2346-2353.

Kamat, P.V., Flumiani, M., Hartland, G.V., 1998. Picosecond dynamics of silver nanoclusters. Photoejection of electrons and fragmentation. J. Phy. Chem. B. 102, 3123-3128.

Mosmann, T., 1983, Rapid colorimetric assay for cellular growth and survival: Application to proliferation and cytotoxicity assays. $\mathrm{J}$. Immunol. Methods. 65, 55-63

Philip, D., 2009. Biosynthesis of Au, Ag and AuAg nanoparticles using edible mushroom extract. Spectrochim. Acta A. Mol. Biomol. Spectroscopy. 73, 374-381.

Rodrigues, C., Asensao, J.S., Bone, T., Valles, J., 2003. An ethnobotanical study of medicinal and aromatic plants in the natural park of 
Serra de S. Mamede (Portugal). J. Ethnopharmacol. 89, 199-209.

Shiv Shankar, S., Rai, A., Ankamwar, B., Singh, A., Ahmad, A., Sastry, M., 2004. Controlling the optical properties of lemongrass-extract synthesized gold nanotriangles and potential application in infrared-absorbing optical coatings. Nature Mat. 3, 482.

Tripathy, A., Raichur, A., Chandrasekaran, N., Prathna, T., Mukherjee, A., 2010. Process variables in biomimetic synthesis of silver nanoparticles by aqueous extract of Azadirachta indica (Neem) leaves. J. Nanoparticle Res. 12, 237-246.

Vigneshwaran, N., Ashtaputre, N. M., Varadarajan, P. V., Nachane, R. P., Panikar, K. M., Balasubrahmanya, R. H., 2007. Extracellular biosynthesis of sivler nanoparticles by Aspergillus flavus, Mater. Lett. 61, 1413-1418.

Zhang, X., Yan, Y., Tyagi, R.D., Surampalli, R.Y., 2011. Synthesis of nanoparticles by microorganisms and their application in enhancing microbial reaction rates. Chemosphere. 82, 489-494.

\section{How to cite this article:}

Nigar Sulthana, R., Rajanikanth, A., 2018. Green synthesis of silver nanoparticles using seed extract of Foeniculum vulgare and their antibacterial activity. Int. J. Curr. Res. Biosci. Plant Biol. 5(7), 77-83. doi: https://doi.org/10.20546/ijcrbp.2018.507.010 